\title{
Small Cell Lung Cancer in a 20-year-old Non-Smoking Man with Systemic Sclerosis
}

\author{
Go Saito ${ }^{1,2}$, Torahiko Jinta ${ }^{1}$, Hiroshi Nakaoka ${ }^{1}$, Atsushi Kitamura ${ }^{1}$, \\ Kenichi Yamaguchi ${ }^{3}$ and Naoki Nishimura ${ }^{1}$
}

\begin{abstract}
Small cell lung cancer (SCLC) is a neuroendocrine tumor, and the median age of onset is about 70 years old. A 20-year-old non-smoking man with known systemic sclerosis presented with discomfort in his left chest. Chest X-ray showed a mass shadow in the left upper zone. A transbronchial lung biopsy revealed small cell carcinoma, and imaging studies reached the diagnosis of extensive disease small cell lung cancer. He had concurrent interstitial lung disease with a non-specific interstitial pneumonia pattern and anti-Scl-70 antibodies. He died eight months after the diagnosis during fifth-line chemotherapy. We herein report the youngest case to date of SCLC with systemic sclerosis.
\end{abstract}

Key words: small cell lung cancer, systemic sclerosis, non-smoker, 20-year-old

(Intern Med 56: 1549-1552, 2017)

(DOI: 10.2169/internalmedicine.56.7985)

\section{Introduction}

Small cell lung cancer (SCLC) is a tumor of neuroendocrine origin (1), accounting for over $10 \%$ of all lung cancers (2). The median age of onset is about 70 years (3). SCLC has a close association with tobacco smoking (4), with over 95\% of SCLC patients being smokers (5). Systemic sclerosis ( $\mathrm{SSc}$ ) is a risk factor for the development of all cancers, although it is most closely associated with lung cancer (6).

We herein report a rare case of a 20-year-old nonsmoking man with known SSc who developed SCLC.

\section{Case Report}

A 20-year-old Japanese man who had been diagnosed with SSc at the age of 17 presented to our department with discomfort in his left chest.

His earliest symptom of SSc was Raynaud's phenomenon, at the age of eight. At age 12, he developed sclerodermatous changes in his hands. He had experienced pneumothorax 4 times since age 14. At 17, he was diagnosed with SSc based on systemic sclerodermatous skin changes and a loss of substance of the distal finger pads. He was positive for anti-Scl70 antibody, and a histological re-examination of a resected lung specimen for treatment of pneumothorax revealed nonspecific interstitial pneumonia (NSIP). Due to the lack of any organ complications, immunosuppressants were not prescribed.

The patient was an undergraduate university student who had never smoked and had no history of exposure to known carcinogens, nor any family history of malignancy. On a physical examination, we detected no abnormalities except for widespread sclerodermatous changes to the head, trunk and limbs.

Laboratory tests showed a white blood cell count of $4.6 \times$ $10^{9} / \mathrm{L}$ with a normal differential count, lactate dehydrogenase (LDH) 256 U/L, Krebs von den Lungen-6 (KL-6) $631 \mathrm{U} / \mathrm{L}$, C-reactive protein (CRP) $0.14 \mathrm{mg} / \mathrm{dL}$, carcinoembryonic antigen (CEA) $2.0 \mathrm{ng} / \mathrm{mL}$, cytokeratin-19 fragments (CYFRA) $2.3 \mathrm{ng} / \mathrm{mL}$, neuron-specific enolase (NSE) $92.6 \mathrm{ng} / \mathrm{mL}$, and pro-gastrin-releasing peptide (ProGRP) $170 \mathrm{pg} / \mathrm{mL}$. Serum cryptococcus antigen, aspergillus antigen, $\beta$-D glucan, antiRNA polymerase III antibody, and anti-centromere antibody were negative.

${ }^{1}$ Division of Pulmonary Medicine, St. Luke's International Hospital, Japan, ${ }^{2}$ Department of Pulmonary Medicine, Seirei Hamamatsu General Hospital, Japan and ${ }^{3}$ Immuno-Rheumatology Center, St. Luke's International Hospital, Japan

Received for publication July 14, 2016; Accepted for publication October 2, 2016

Correspondence to Dr. Torahiko Jinta, jintato@luke.ac.jp 


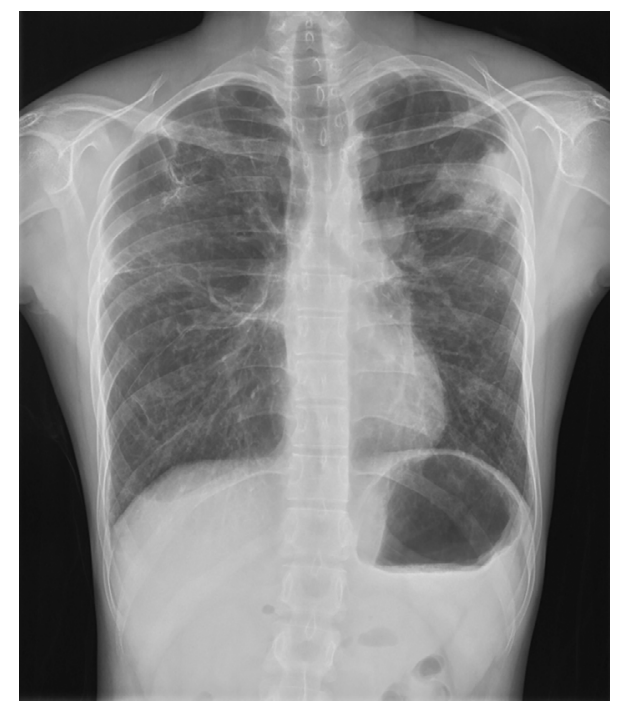

Figure 1. Chest $\mathrm{X}$-ray showed a mass shadow in the peripheral area of the left upper zone, and widespread diffuse reticular shadows.

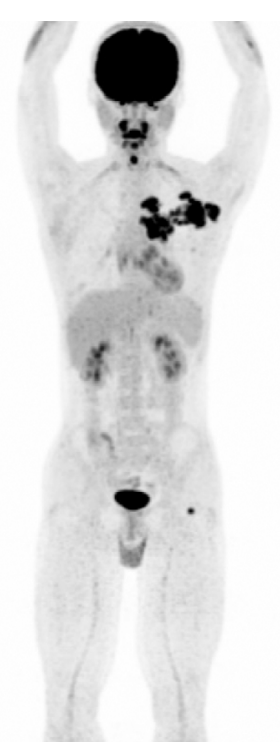

Figure 3. PET-CT revealed high accumulation in the left upper lobe mass (standardized uptake value max: SUVmax 9.5) (Fig. 3), the left para-spinal mass (SUVmax 10.4), enlarged lymph nodes, and the left femoral head (SUVmax 8.0)

Chest X-ray showed a mass shadow in the peripheral area of the left upper zone (Fig. 1). A computed tomography (CT) scan of the chest revealed a mass in the left upper lobe, with pleural infiltration, enlarged lymph nodes, and a left paraspinal mass. There were upper-lobe dominant cystic spaces that were considered to be pathologically correlated with progressive-stage interstitial lung disease (ILD) (Fig. 2). On lung function tests, the percent predicted volume capacity (\%VC) was $55.3 \%$, and the forced expiratory volume percentage in 1 second (forced expiratory volume (FEV) $1.0 \%$ ) was $94.7 \%$. Positron emission tomography (PET)-CT revealed high accumulation in the left upper lobe mass, the left paraspinal mass, the enlarged lymph nodes,

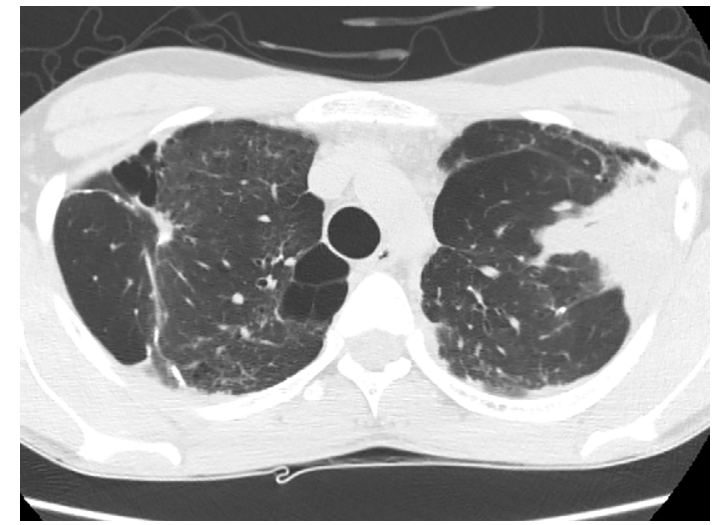

Figure 2. A computed tomography (CT) scan of the chest revealed a mass in the left upper lobe $(S 3 ; 4.1 \times 6.4 \times 4.5 \mathrm{~cm})$ with features suggestive of pleural infiltration, and marked enlargement of the left hilar, superior mediastinal, para-aortic, and axillary lymph nodes. There was a separate left para-spinal mass $(4.3 \times 3.0 \mathrm{~cm})$ progressing into the vertebral canal at the Th5 vertebral level. There were also upper lobe dominant cystic spaces.

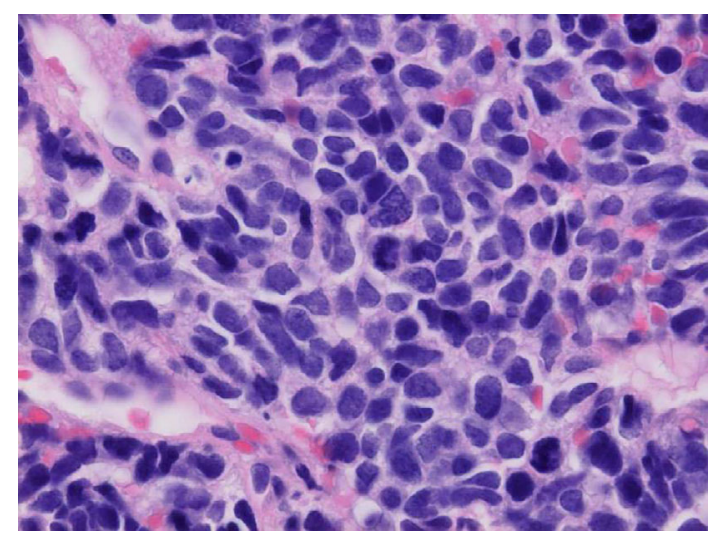

Figure 4. A transbronchial biopsy of the left upper lobe mass revealed small-sized tumor cells possessing minimal cytoplasm and hyperchromatic indistinct nucleoli with abnormal mitosis. (Original Magnification)

and the left femoral head (Fig. 3). CT, PET-CT, and magnetic resonance imaging (MRI) of the brain revealed no metastatic lesions to any organs except the left femoral head. A transbronchial lung biopsy of the left upper lobe mass revealed small cell carcinoma with neuroendocrine characteristics (Fig. 4, 5). Based on these findings, he was diagnosed with extensive-disease SCLC (T3N2M1b, clinical staging).

Chemotherapy was commenced with cisplatin $\left(80 \mathrm{mg} / \mathrm{m}^{2}\right.$ on day 1) plus etoposide $\left(100 \mathrm{mg} / \mathrm{m}^{2}\right.$ on days $\left.1-3\right)$. The left para-spinal mass had progressed into the vertebral canal, nearly invading the spinal cord. Therefore, we performed concurrent bilateral irradiation to the paravertebral mass of 30 Gray (Gy) in 10 fractions over 12 days. The tumor responded to the first cycle of the chemotherapy without adverse events of grade 3 or more, but after 4 cycles, the tumor progressed. As second-line chemotherapy, we avoided 
Synaptophysin

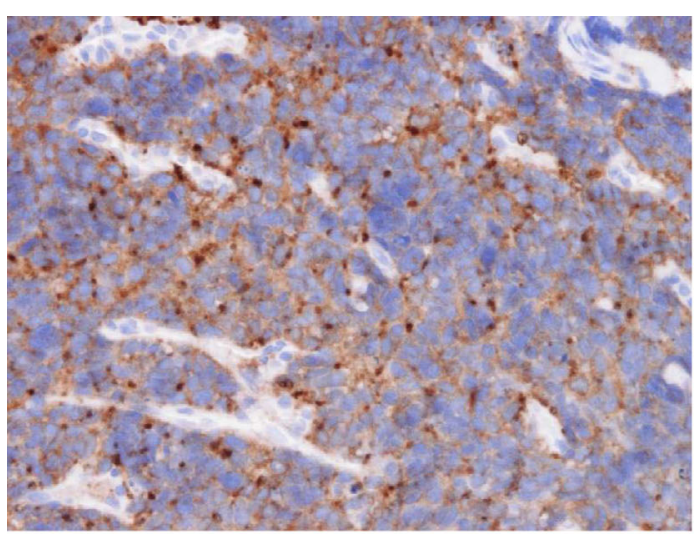

(Original Magnification)
Chromogranin

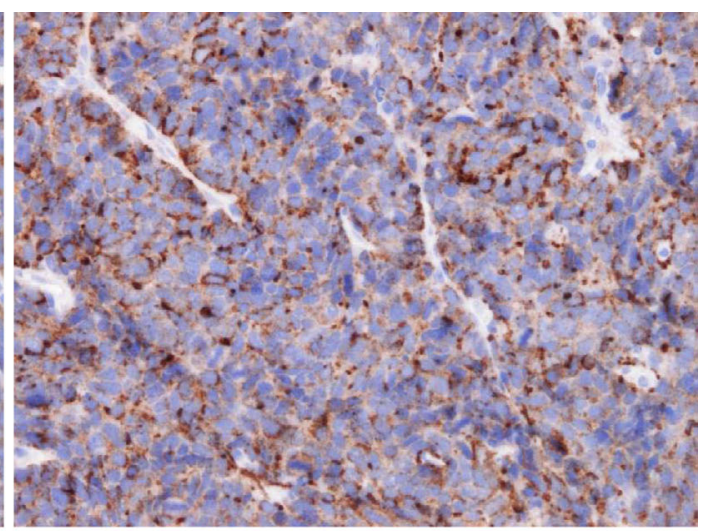

(Original Magnification)

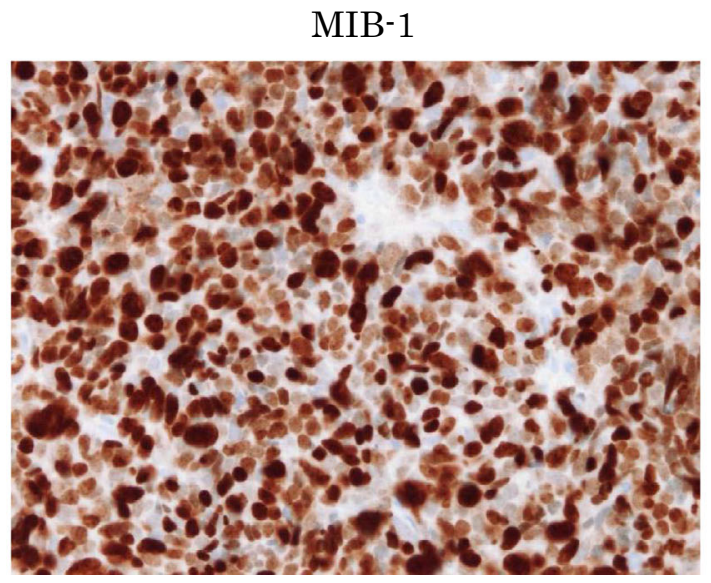

(Original Magnification)

Figure 5. Immunohistochemical staining revealed that the tumor cells were positive for chromogranin A, synaptophysin, and thyroid transcription factor-1 (TTF-1), and negative for p40. Ki-67 antigen (MIB-1) labeling index was $96 \%$.

irinotecan and amrubicin, which can easily cause exacerbation of ILD, and chose topotecan therapy $\left(1 \mathrm{mg} / \mathrm{m}^{2}\right.$ on days 1-5). However, after two weeks the enlarged left hilar lymph nodes caused constriction of the left main bronchus, and head MRI revealed three brain metastatic lesions. External beam therapy in 4-field box treatment to the lymph nodes (30 Gy in 10 fractions over 15 days) and gamma knife therapy (margin dose: $18 \mathrm{~Gy}$ ) were performed with $8 \mathrm{mg} /$ day dexamethasone. After radiotherapy, he received weekly paclitaxel therapy $\left(80 \mathrm{mg} / \mathrm{m}^{2}\right.$ on days 1,8 , and 15$)$ as thirdline chemotherapy. During the third course, head MRI revealed multiple new brain metastases, and cranial irradiation (30 Gy in 10 fractions over 14 days) was given. Vinorelbine therapy $\left(25 \mathrm{mg} / \mathrm{m}^{2}\right.$ on days 1,8 , and 15$)$ as fourth-line chemotherapy resulted in progressive disease, so he began S-1 therapy $(50 \mathrm{mg} / \mathrm{dose}$, twice a day on days 1-28) but eventually died of respiratory failure 8 months after the diagnosis. Consent for autopsy could not be obtained.

\section{Discussion}

SCLC is uncommon in the young $(7,8)$. SCLC in SSc patients is considered to be rare, but the incidence rate is unclear (9-11). Furthermore, SCLC among non-smokers is very rare $(5,12)$. To our knowledge, the youngest cases with SCLC are a 14-year-old boy and a 14-year-old girl in the literature $(13,14)$, but to our knowledge, this is the youngest case of SCLC in an SSc patient. Several reports have described the characteristics of lung cancer in patients with $\operatorname{SSc}(6,15,16)$; the proportion of women is higher than in the general population, and the most frequent pathological type is adenocarcinoma. SCLC is known to have more gene mutations than non-SCLC in non-smokers (17); it is therefore possible that there were some additional triggers influencing the development of SCLC in such a young nonsmoker.

The development of lung cancer in SSc patients has long been considered to be associated with pulmonary fibrosis (6). It has been reported that idiopathic pulmonary fibrosis (IPF) patients have an increased risk of lung cancer $(18,19)$, but the relationship between other types of ILD and lung cancer is unclear.

Several reports have discussed the possible relationship between autoantibodies and cancer (20-23). In our case, the 
patient had anti-Scl 70 antibody. Foeldvari et al. reported that, in a group of SSc patients with a young onset, the rate of anticentromere antibody positivity was low (21). Colaci et al. reported that anti-Scl-70 antibodies are associated with an increased risk of developing lung cancer in Italy (15). In contrast, Shah et al. stated that patients with anti-Scl-70 antibody or anti-centromere antibody positivity tended to have a longer interval between the SSc onset and the cancer diagnosis (22), whereas this interval was relatively short among SSc patients with autoantibodies to RNA polymerase I/III. Furthermore, Joseph et al. showed that SSc patients with autoantibodies to RNA polymerase III subunit (RPC1) often develop cancer before the onset of SSc (23). Interestingly, this study suggests that cancer can induce the development of anti-RPC1 antibody-positive SSc. In other words, cancer itself can induce autoimmune disease through autoantibodies.

In our case, the patient had anti-Scl-70 antibody, not antiRPC1 antibody, and he developed SCLC 12 years after the onset of SSc. In addition, the hypothesis that SSc patients can develop cancer through a specific autoantibody has not been demonstrated to date. However, given that cancer can induce the development of autoimmune disease through a specific autoantibody, it may be possible that autoimmune disease can induce the development of cancer through a specific autoimmunity.

In conclusion, we were unable to determine the mechanisms by which our young non-smoker developed SCLC. This highlights the importance of performing a molecular biological analysis, such as detecting genetic defects using a next-generation sequencer, in such rare cases in order to gain further insight about the development of cancer and autoimmune diseases and the relationship between these complex disorders.

The authors state that they have no Conflict of Interest (COI).

\section{References}

1. Benatar M, Blaes F, Johnston I, et al. Presynaptic neuronal antigens expressed by a small cell lung carcinoma cell line. J Neuroimmunol 113: 153-162, 2001.

2. Govindan R, Page N, Morgensztern D, et al. Changing epidemiology of small-cell lung cancer in the United States over the last 30 years: analysis of the surveillance, epidemiologic, and end results database. J Clin Oncol 24: 4539-4544, 2006.

3. Behera M, Ragin C, Kim S, et al. Trends, predictors, and impact of systemic chemotherapy in small cell lung cancer patients between 1985 and 2005. Cancer 122: 50-60, 2016.

4. Pleasance ED, Stephens PJ, O'Meara S, et al. A small-cell lung cancer genome with complex signatures of tobacco exposure. Nature 463: 184-190, 2010.

5. Muscat JE, Wynder EL. Lung cancer pathology in smokers, exsmokers and never smokers. Cancer Lett 88: 1-5, 1995.
6. Bonifazi M, Tramacere I, Pomponio G, et al. Systemic sclerosis (scleroderma) and cancer risk: systematic review and meta-analysis of observational studies. Rheumatology (Oxford) 52: 143-154, 2013.

7. Sekine I, Nishiwaki Y, Yokose T, et al. Young lung cancer patients in Japan: different characteristics between the sexes. Ann Thorac Surg 67: 1451-1455, 1999.

8. Putnam JS. Lung carcinoma in young adults. JAMA 238: 35-36, 1977.

9. Kanaji N, Fujita J, Bandoh S, et al. Small cell lung cancer associated with systemic sclerosis. Intern Med 44: 315-318, 2005.

10. Katzen JB, Raparia K, Agrawal R, et al. Early stage lung cancer detection in systemic sclerosis does not portend survival benefit: a cross sectional study. PLoS One 10: e0117829, 2015.

11. Saha K, Saha A, Panchadhyayee $P$, et al. Small cell lung carcinoma associated with progressive systemic sclerosis. Maedica (Buchar) 8: 351-354, 2013.

12. Sun JM, Choi YL, Ji JH, et al. Small-cell lung cancer detection in never-smokers: clinical characteristics and multigene mutation profiling using targeted next-generation sequencing. Ann Oncol 26: 161-166, 2015

13. Kim CK, Chung CY, Koh YY. Primary small cell bronchogenic carcinoma in a 14-year-old boy. Pediatr Pulmonol 29: 317-320, 2000 .

14. Trønnes H, Haugland HK, Békássy AN, Helle SI, Sorbye H. Small cell lung cancer in a 14-year-old girl. J Pediatr Hematol Oncol 34: e86-e88, 2012.

15. Colaci M, Giuggioli D, Sebastiani M, et al. Lung cancer in scleroderma: results from an Italian rheumatologic center and review of the literature. Autoimmun Rev 12: 374-379, 2013.

16. Yang Y, Fujita J, Tokuda M, Bandoh S, Ishida T. Lung cancer associated with several connective tissue diseases: with a review of literature. Rheumatol Int 21: 106-111, 2001.

17. Vogelstein B, Papadopoulos N, Velculescu VE, Zhou S, Diaz LA Jr, Kinzler KW. Cancer genome landscapes. Science 339: 15461558, 2013.

18. Le Jeune I, Gribbin J, West J, Smith C, Cullinan P, Hubbard R. The incidence of cancer in patients with idiopathic pulmonary fibrosis and sarcoidosis in the UK. Respir Med 101: 2534-2540, 2007.

19. Ozawa Y, Suda T, Naito T, et al. Cumulative incidence of and predictive factors for lung cancer in IPF. Respirology 14: 723-728, 2009.

20. Wooten M. Systemic sclerosis and malignancy: a review of the literature. South Med J 101: 59-62, 2008.

21. Foeldvari I, Tyndall A, Zulian F, et al. Juvenile and young adultonset systemic sclerosis share the same organ involvement in adulthood: data from the EUSTAR database. Rheumatology (Oxford) 51: 1832-1837, 2012.

22. Shah AA, Rosen A, Hummers L, Wigley F, Casciola-Rosen L. Close temporal relationship between onset of cancer and scleroderma in patients with RNA polymerase I/III antibodies. Arthritis Rheum 62: 2787-2795, 2010.

23. Joseph CG, Darrah E, Shah AA, et al. Association of the autoimmune disease scleroderma with an immunologic response to cancer. Science 343: 152-157, 2014.

The Internal Medicine is an Open Access article distributed under the Creative Commons Attribution-NonCommercial-NoDerivatives 4.0 International License. To view the details of this license, please visit (https://creativecommons.org/licenses/ by-nc-nd/4.0/).

(C) 2017 The Japanese Society of Internal Medicine http://www.naika.or.jp/imonline/index.html 